\title{
Pitch based carbon fibers for automotive body and electrodes
}

\author{
Kap Seung Yang ${ }^{1, *}$, Bo-Hye Kim² and Seong-Ho Yoon $^{3}$ \\ ${ }^{1}$ School of Polymer Science and Engineering/Department of Polymer Engineering, Graduate School/Alan MacDiarmid Energy Research \\ Institute, Chonnam National University, Gwangju 500-757, Korea \\ ${ }^{2}$ Division of Science Education, Daegu University, Gyeongsan 712-714, Korea \\ ${ }^{3}$ Institute for Materials Chemistry and Engineering, Kyushu University, Kasuga, Fukuoka 816-8580, Japan
}

\section{Article Info}

Received 17 June 2014

Accepted 12 July 2014

*Corresponding Author

E-mail: ksyang@chonnam.ac.kr

\section{Open Access}

DOI: http://dx.doi.org/

10.5714/CL.2014.15.3.162

This is an Open Access article distributed under the terms of the Creative Commons Attribution Non-Commercial License (http://creativecommons.org/licenses/ by-nc/3.0/) which permits unrestricted non-commercial use, distribution, and reproduction in any medium, provided the original work is properly cited.

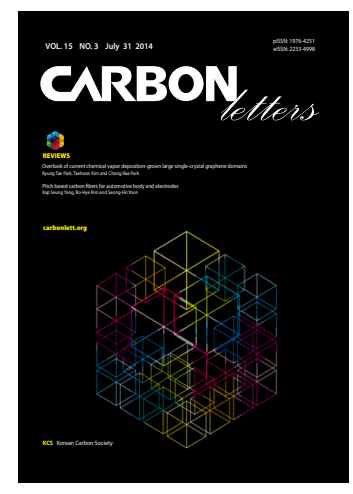

http://carbonlett.org

pISSN: 1976-4251

elSSN: 2233-4998

Copyright $\odot$ Korean Carbon Society

\begin{abstract}
Pitch is an attractive raw material for carbon fiber precursors due to its low cost stemming from its availability as a residue of coking and petroleum processes. Ford Motor Company reported a carbon fiber target price of $\$ 11.0 / \mathrm{kg}$ by using a fast cycle-time manufacturing method with carbon fiber in an inexpensive format, allowing for an average retail price of gasoline of $\$ 3.58 /$ gallon. They also recommended the use of carbon fiber with strength of $1700 \mathrm{MPa}$, modulus of $170 \mathrm{GPa}$, and $1.5 \%$ elongation. This study introduced a ca. $5.5 \mu \mathrm{m}$ carbon fiber with $2000 \mathrm{MPa}$ tensile strength obtained from a precursor through simple distillation of petroleum residue. Petroleum pitch based carbon nanofibers prepared via electrospinning were characterized and potential applications were introduced on the basis of their large specific surface area and relatively high electrical conductivity.
\end{abstract}

Key words: pitch based carbon fiber, automotive body application, mechanical property, electrospinning, electrode

\section{Introduction}

Demand for various types of carbon fibers has recently increased owing to both their desirable mechanical properties and cost-effectiveness. The respective mechanical properties of commercial polyacrylonitrile (PAN)/mesophase pitch-based carbon fibers are 3.0-5.7 GPa/1.4-2.2 GPa tensile strength; 230-300 GPa/140-820 GPa tensile modulus; and 1.3\%$1.9 \% / 0.2 \%-1.1 \%$ elongation. PAN-based carbon fibers exhibit higher tensile strength and larger elongation, thereby lending greater flexibility, although their modulus is relatively lower when compared to that of mesophase pitch-based carbon fibers. The mechanical properties of commercial fibers exceed those of commonly used steel and aluminum. On the other hand, the mechanical properties of pitch-based general-purpose carbon fibers exhibit a wide gap relative to those previously mentioned by $0.5-1.0 \mathrm{GPa}$ tensile strength, 30-40 GPa modulus, and 1.4\%-2.4\% elongation. The requirements for carbon fiber products used in automotive applications are considerably lower than what is currently available, as shown in Table 1. For example, Jim deVries at Ford Motor Company [1] recommended the use of carbon fiber with a strength of $1700 \mathrm{MPa}$, modulus of $170 \mathrm{GPa}$, and $1.5 \%$ elongation.

In this sense, there is a strong demand for carbon fibers that possess properties within the vacancies that are not covered by general-purpose pitch-based carbon fibers and highperformance carbon fibers, including those based on PAN and mesophase pitch. Such carbon fibers can be realized via design of the molecular structure of the precursor pitch from selected residues $[2,3]$.

It has recently become necessary to reduce the weight of automobiles in order to allow the adoption of electrical vehicles. Carbon fiber composites are the best choice among existing materials, and the only hurdle for carbon fibers is their prohibitive cost for application to commercial automobiles. Accordingly, there is a strong demand in the automotive indus- 
Table 1. Properties of carbon fibers available for commercial use and requirements for automotive applications [1]

\begin{tabular}{ccc} 
Reinforcing fibers & Strength (MPa) & Modulus (GPa) \\
\hline Glass & 3400 & 72 \\
Commodity carbon & 3600 & 225 \\
Aerospace carbon (T700) & 4900 & 230 \\
Automotive goal & 1700 & 170 \\
\hline
\end{tabular}

http://web.ornl.gov/sci/physical_sciences_directorate/mst/PMC/carbon_fiber09/agenda.html.

try for carbon fibers with lower cost and moderate mechanical properties.

Pitch is an attractive raw material for use as a carbon fiber precursor due to its low cost stemming from its availability as a residue of coking and petroleum processes. PAN-based carbon fibers have a relatively high cost of US\$20-30/ $\mathrm{kg}$, and mesophase pitch-based carbon fibers are even much more expensive, although their mechanical properties are excellent. The cost of carbon fibers must be competitive when compared to $\mathrm{Al}$ for body panels. Jim deVries at Ford Motor Company reported a carbon fiber target price of $\$ 11.0 / \mathrm{kg}$ obtainable by using a fast cycletime manufacturing method with carbon fiber in an inexpensive format [1-7], allowing for an average retail price of gasoline of \$3.58/gallon over 72 months since 2003 .

Also, carbon nanofibers (CNFs) have potential for use in various new applications such as electrodes, catalyst supports, adsorbents, composites, etc., due to their large surface area and relatively high electrical conductivity.

\section{Pitch Synthesis}

Pitches are residues from refining petroleum oils and coal, and are mixtures that consist of condensed aromatic molecules with a wide range of relative molecular weights. Pitch precursors (PPs) for carbon fibers are synthesized by condensation of the residues from coking or petroleum processes. The condensation methods generally used are air blowing for dehydration condensation [3,7,8], supercritical extraction [9-12], and halgenatation/dehydohalgenation [13-17], and these processes are followed by distillation and thermal treatment. The average molecular structures of the precursors are sensitively dependent on the source of the raw material and on the condensation methods used. The characteristics of the carbonized fibers are also very sensitively dependent on the precursor material and on the processing conditions, such as the stabilization and carbonization.

The composition of petroleum pitches varies to a significant degree depending on the feed stock used for the production and processes that are applied. The common feature of a petroleumbased pitch is $10 \%-20 \%$ lower aromaticity than that of coal tar pitch. Accordingly, petroleum-based pitches contain a higher portion of alkyl substituted and partially hydrogenated polycyclic aromatic hydrocarbons. The molecular weight distribution of the petroleum-sourced pitch is broader, and the average molecular weights are higher when compared to that of coal tar-
Table 2. Comparison of pitches prepared via various methods

\begin{tabular}{cccccc}
\multirow{2}{*}{ Pitch } & S.P $\left({ }^{\circ} \mathrm{C}\right)$ & \multicolumn{2}{c}{ Solubility (\%) } & \multirow{H}{H}{$/ \mathrm{C}$} & Mw \\
\cline { 3 - 4 } & & HI & THFI (PI) & (molar ratio) & \\
\hline AN-PP & 256 & 96.7 & 0.72 & 0.67 & 556 \\
Cl-PP & 292 & 97.2 & 0 & 0.75 & 2380 \\
Br-mNP & $219-249$ & 60.0 & 0 & $0.70-0.73$ & $913-1694$
\end{tabular}

$\mathrm{HI}$ : hexane insoluble, THFI: tetrahydrofuran insoluble, PI: pyridine insoluble, PP: pitch precursor.

based pitch [18-22].

Three kinds of pitches are discussed with respect to their properties, and respective applications on the basis of these properties are sought. The precursor pitches used are prepared via thermal treatment (Anshan East Asia Carbon Fiber Co., China, AN-PP); from petroleum-based PPs prepared through condensation of pyrolyzed fuel oil (PFO) with $\mathrm{Cl}_{2}$ (Hanwha Chemical Co., Korea, Cl-PP) [16,17]; and from bromination of 2-methylnaphalene followed by dehydrobromination/polymerization and extraction in $\mathrm{n}$-hexane to eliminate light components (Br-mNP) [23]. The properties of the pitches are summarized in Table 2.

The data show that the solubilities of Cl-PP and $\mathrm{Br}-\mathrm{mNP}$ are much higher than that of AN-PP. Accordingly, higher solubility enables measurement of relatively higher molecular weight, and a higher $\mathrm{H} / \mathrm{C}$ value of a chemically synthesized pitch represents more aliphatic groups than that of AN-PP. The solid ${ }^{13} \mathrm{C}$ and ${ }^{1} \mathrm{H}$ nuclear magnetic resonance (NMR) spectra of AN-PP and Cl-PP show broad peaks at $0-50 \mathrm{ppm}$ and $100-150 \mathrm{ppm}$, but there is a more intensive peak for $\mathrm{Cl}-\mathrm{PP}$ at $0-50 \mathrm{ppm}$ of ${ }^{13} \mathrm{C}$ and at $1-3 \mathrm{ppm}$ of ${ }^{1} \mathrm{H}$ NMR [24] (Figs. 1 and 2).

The spectra indicate that the chemically synthesized Cl-PP and $\mathrm{Br}-\mathrm{mNP}$ pitches contain more abundant aliphatic groups with more hydrogen when compared to that of AN-PP. The ${ }^{13} \mathrm{C}$ data of Br-mNP presented a newly formed $\mathrm{C}_{4}$ that increased with an increasing degree of 2-methylnaphthalene polymerization in the as-prepared pitches $[23,24]$. The flexible methylene crosslinkage between the naphthalene units contributes to the solubility and linearity of the molecule to be formed as a flexible fiber precursor. The average molecular structures of the three pitches proposed are shown in Fig. 3

The solution properties were investigated for the same concentration and temperature levels [24]. The electrical conductivity and viscosity of Cl-PP were $0.15 \mu \mathrm{S} / \mathrm{cm}$ and $739 \mathrm{cP}$, respectively, while those for AN-PP were $0.35 \mu \mathrm{S} / \mathrm{cm}$ and $629 \mathrm{cP}$. A higher viscosity and lower electrical conductivity was observed for Cl-PP than for AN-PP. The respective behaviors of Cl-PP are expected from a molecular structure with a lower aromatic component but higher molecular weight, and vice-versa. The lower electrical conductivity of Cl-PP would be beneficial for higher charge density on the jet surface and higher viscosity rusting for better spinnabilty in electrospinning. The PPs can be electrospun into fibers of 2-5 $\mu \mathrm{m}$ in diameter from Cl-PP and 1-2 $\mu \mathrm{m}$ from Br-mNP $[23,25]$.

Kim et al. [26] observed rheological behaviors of two isotropic pitches prepared via bromination (Br-EB) and thermal 
(a)

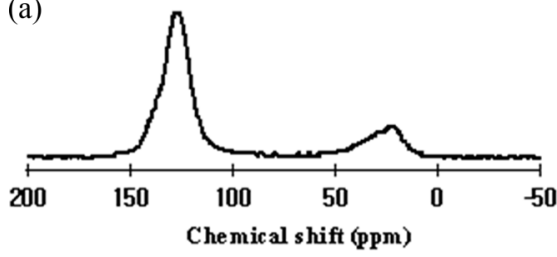

(b)

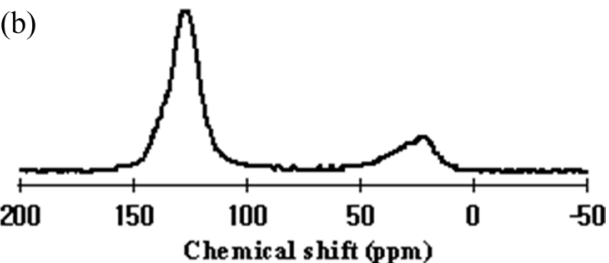

Fig. 1. ${ }^{13} \mathrm{C}$ NMR spectra; (a) Cl-PP, (b) AN-PP. NMR: nuclear magnetic resonance, PP: pitch precursor.

(a)

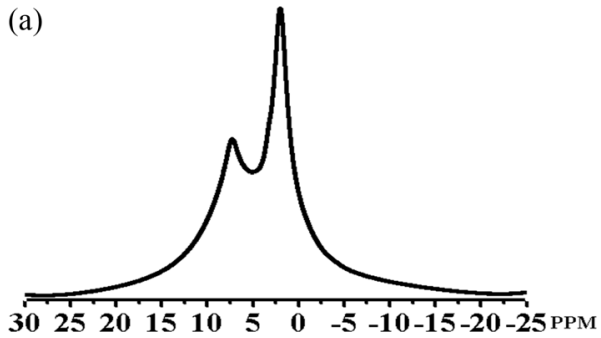

(b)

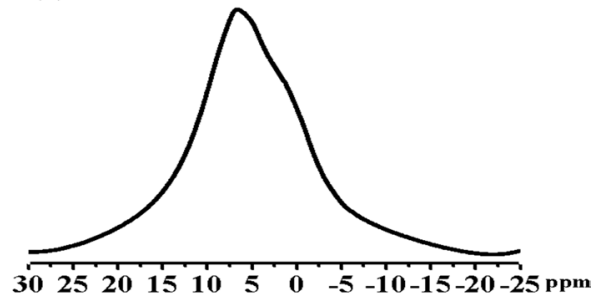

Fig. 2. 'H NMR spectra; (a) CI-PP, (b) AN-PP. NMR: nuclear magnetic resonance, PP: pitch precursor.

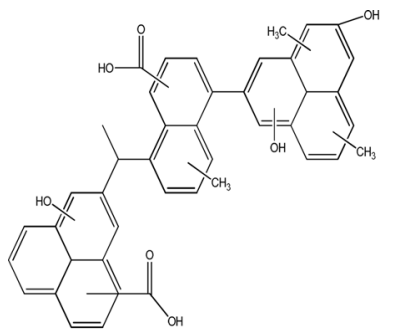

(a)

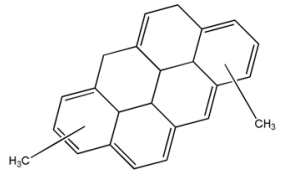

(b)

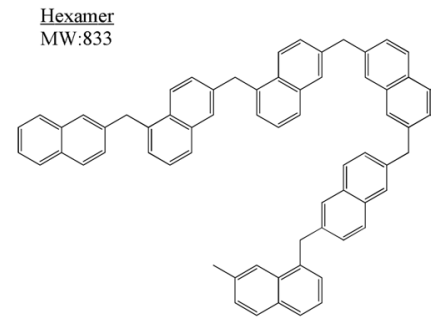

(c)

Fig. 3. Average molecular structures of (a) Cl-PP, (b) AN-PP, and (c) Br-mNP pitches. PP: pitch precursor.

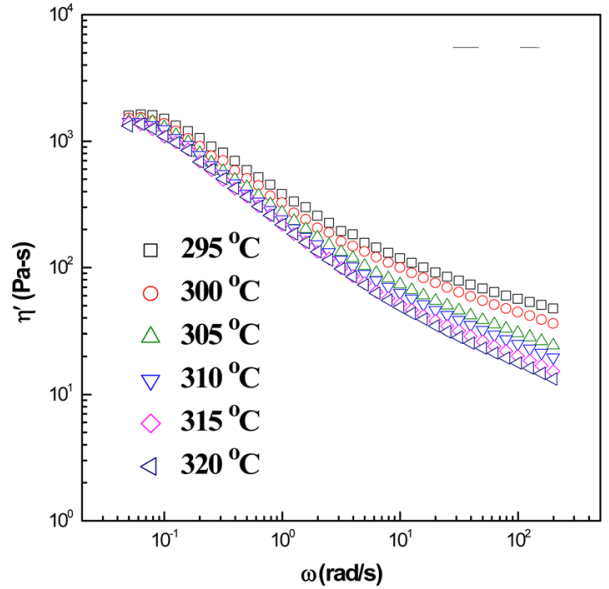

(a) $\mathrm{EB}-\mathrm{Br}(\mathrm{Br}-\mathrm{EB})$

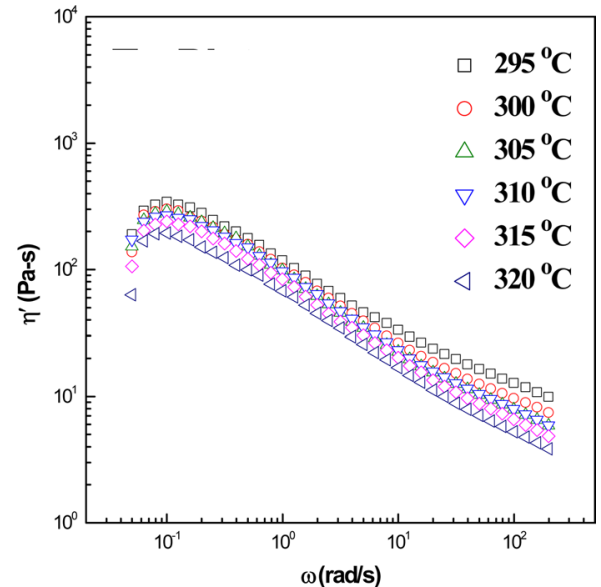

(b) EB-Dist (Th-EB)

Fig. 4. The $\eta^{\prime}$ curves of Br-EB and Th-ED showing the effects of temperature [26].

distillation (Th-EB) of ethylene bottom oil as a raw material. The rheological properties of the pitches were measured using an Advanced Rheometric Expansion System (ARES, TA
Instruments, USA) under nitrogen purging. Fig. 4 exhibits the dynamic viscosity $\left(\eta^{\prime}\right)$ curves of the Br-EB and Th-EB at various temperatures. Commercial isotropic pitches are reported to 
show Newtonian flow behavior [27-34]. However, Br-EB and Th-EB exhibit Bingham behavior, suggesting that Br-EB and Th-EB have a molten state similar to that of mesophase pitches. Moreover, Br-EB has larger values of $\eta^{\prime}$ than Th-EB does in the whole frequency range, probably as a result of its higher molecular weight.

Hanwha Co. produced precursor pitches of various softening points at a pilot scale via condensation of PFO through chlorination/dehydrochlorination (HPCP-67). The properties of the precursor pitch and of the fibers carbonized at $1000^{\circ} \mathrm{C}$ are summarized in Tables 3 and 4, respectively.

Kim et al. [2] utilized naphtha cracking residue to enhance the mechanical properties targeting automotive applications for carbon fiber composites. They synthesized a rather linear molecular structure through bromination/dehydrobromination of the naphtha cracking residue. The carbon fibers prepared via melt spinning of brominated ethylene bottom (Br-EB) were characterized to have ca. $7 \mu \mathrm{m}$ diameter and $1800 \mathrm{MPa}$ tensile strength, which are superior to those of a precursor obtained through a simple distillation method (Th-EB) for the same fiber diameter range. They also reported a simple and cost effective process to prepare carbon fibers with $7 \mu \mathrm{m}$ diameter, $1500 \mathrm{MPa}$ tensile strength, and $3.2 \%$ elongation via heat treatment at $800^{\circ} \mathrm{C}$ for 5 min only.

Table 3. Select properties of precursor pitch of HPCP-67

\begin{tabular}{ccccccc} 
& \multirow{5}{*}{$\begin{array}{c}\text { SP } \\
\text { Pitch }\end{array}$} & \multicolumn{5}{c}{ Solubility (\%) } \\
\cline { 3 - 6 } HPCP-67 & $\left({ }^{\circ} \mathrm{C}\right)$ & HI & TS & TI-PS & PI & \\
\cline { 2 - 6 } & 295 & 95.2 & 62.8 & 36.4 & 0.8 & 0.69 \\
\hline
\end{tabular}

HI: hexane insoluble, TS: toluene soluble, TI: toluene insoluble, PS: pyridine soluble, PI: pyridine insoluble.

Table 4. The characteristics of carbonized fibers from HPCP-67 at $1000^{\circ} \mathrm{C}$

\begin{tabular}{ccc}
$\begin{array}{c}\text { Fiber diameter } \\
(\mu \mathrm{m})\end{array}$ & $\begin{array}{c}\text { Tensile strength } \\
(\mathrm{MPa})\end{array}$ & $\begin{array}{c}\text { Tensile modulus } \\
(\mathrm{MPa})\end{array}$ \\
\hline 15 & 1123 & 39000 \\
\hline
\end{tabular}

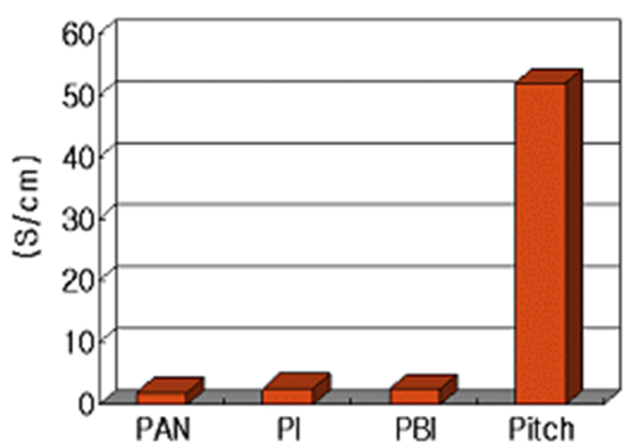

(a)
Even higher tensile strength of $2000 \mathrm{MPa}$ was obtained from the precursor from simple distillation (Th-EB) at fiber diameter of ca. $5.5 \mu \mathrm{m}$. The mechanical properties of the composite satisfied tensile strength requirements with an adequate modulus and elongation for automotive requirements.

\section{Pitch Based CNFs from Electrospinning}

Carbon nanomaterials, such as graphene and carbon nanotubes, present excellent performance on the basis of their specific gravimetric density. There are hurdles to increase the specific volumetric density for electrode applications, however, in order to approach high volumetric energy density. Nano-sized carbon fibers from electrospinning are one of the promising technologies that can meet these demands $[35,36]$.

The strengths of electrospinning are that it can achieve the following:

- Large specific surface area for super capacitor applications, catalyst support

- Large aspect ratio as a self-standing material, and low volume fraction for electron conduction

- Easy fiber formation process for blended multi-function materials; pore size control can be achieved with the help of additives

- Feasible mass production without catalysts for low-cost production as electrode materials

- Tunable volumetric density via alignments of individual fibers $[35,36]$.

The electrospinning of the pitch is dependent on the viscosity and on the stretchability that results from the molecular structure, tunable via a synthetic method, of the raw materials. Cl-PPbased carbon fibers from electrospinning showed much higher electrical conductivity $(50 \mathrm{~S} / \mathrm{cm})$ and higher specific surface area $\left(2054 \mathrm{~m}^{2} / \mathrm{g}\right)$ with wider pore diameter $(25 \AA)$ than those from polymer-based electrospun CNFs (Figs. 5a and b) [37,38].

Park et al. [25,37] performed electrospinning of $40 \mathrm{wt} \% \mathrm{Cl}-$ $\mathrm{PP}$ in tetrahydrofuran (THF). Scanning electron microscopy (SEM) photographs of the carbonized fibers with diameters of 2-5 $\mu \mathrm{m}$ from Cl-PP are shown in Fig. 6. Koombhongse et al. [39] also reported that these types of fibers could be formed via

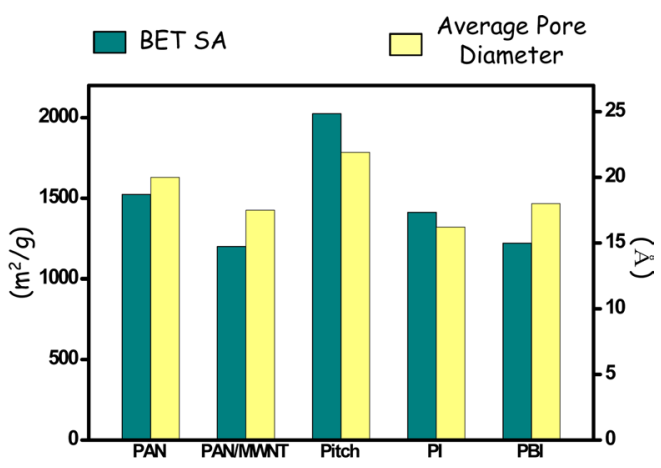

(b)

Fig. 5. Characteristics of electospun carbon nanofibers [37,38]. PAN: polyacrylonitrile, PI: polyimide, PBI: polybenzimidazole. 
solvent evaporation followed by flattening [39-44]. Pitch Cl-PP showed better spinnability in terms of the regular shape of the fibers as compared to that of AN-PP. The carbonization yield of the pitch Cl-PP electrospun fibers was $3 \%$ less than that of AN-

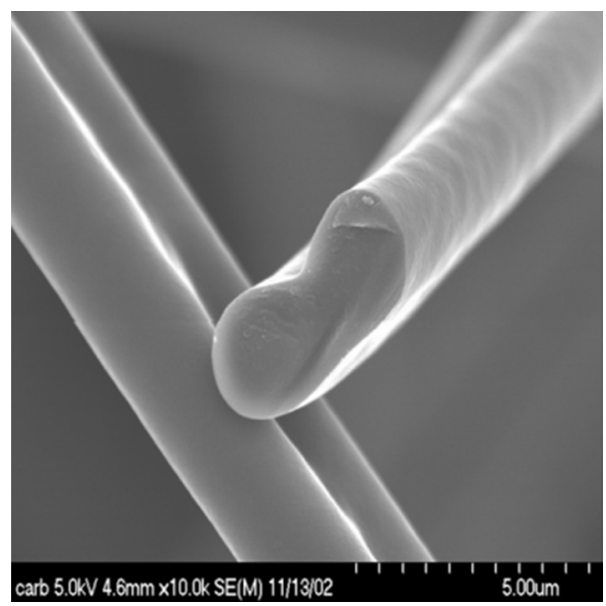

Fig. 6. Scanning electron microscopy microphotographs of the crosssectional direction of carbonized fiber from CI-PP. PP: pitch precursor.

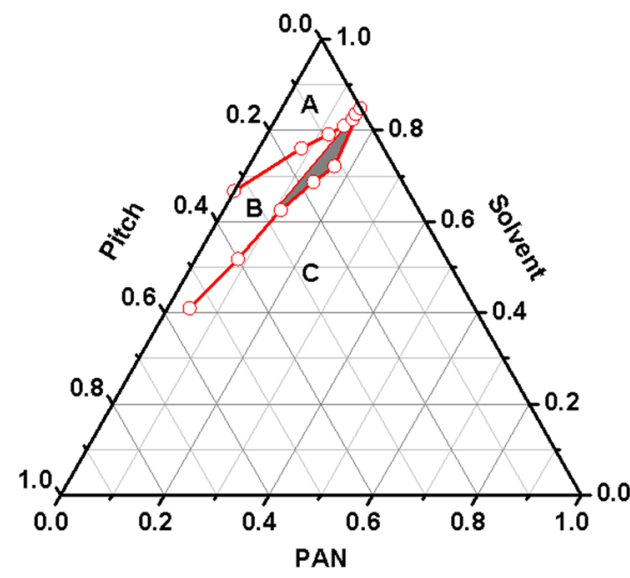

(a) PAN/AN-PP
PP electrospun fibers at $600^{\circ} \mathrm{C}$, which results in a higher carbonization yield from the pitch with a higher aromaticity. Moreover, steam activation of the pitch Cl-PP-based carbon fibers showed a higher burn-off percentage than the AN-PP-based fibers. The activation energy of the respective carbon fibers was determined to be of $92.05 \mathrm{~kJ} / \mathrm{mol}$ for Cl-PP-based and $108 \mathrm{~kJ} / \mathrm{mol}$ for ANPP-based fibers, indicating that the former were more rapidly activated.

\section{Pitch and PAN Blends}

The PAN-pitch-solvent ternary phase diagram is presented in Fig. 7a [45-49]. Phase A indicates a homogeneous solution, phase $\mathrm{B}$ indicates a biphasic solution, and phase $\mathrm{C}$ indicates a mixture of a solid solute and a solvent. The shaded region in phase B denotes high spinnability, which is suitable for the formation of homogeneous nano-fibers. The ternary phase diagrams show that the phase B is wider that for PAN/Cl-PP, representing wider spinnable compositions from a higher solubility of the Cl-PP than the AN-PP.

The spinnability of pitch electrospinning could be obtained by blending a polymer of excellent spinnability such as PAN [50]. PAN/Cl-PP and PAN/AN-PP blend solutions were pre-

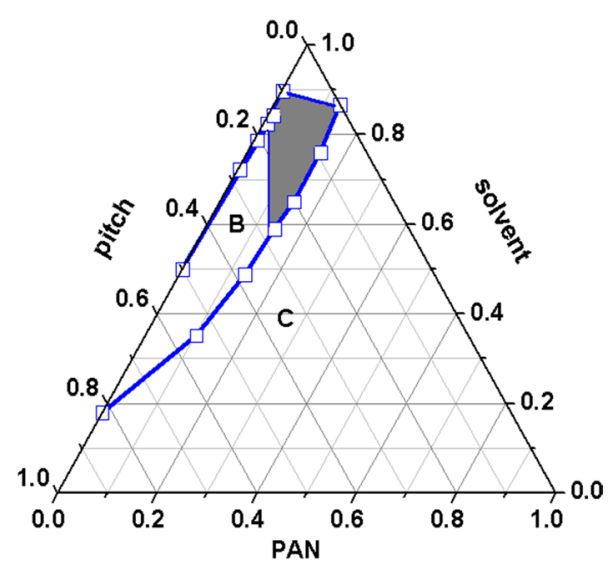

(b) PAN/Cl-PP

Fig. 7. Ternary phase diagram of polyacrylonitrile (PAN)/pitch/solvent; PAN in dimethylformamide and pitch in tetrahydrofuran solvent. Phase A, homogeneous solution; Phase B, biphasic solution; Phase C, mixture of solid solute and solvent; shadow region in phase B; spinnable composition [45]. PP: pitch precursor.

Table 5. Electrical conductivities of the single carbon nanofibers of various pitch concentrations measured by current-voltage profile in a range of -1.0 to $1.0 \mathrm{~V}$.

\begin{tabular}{cccccc} 
Sample & $\mathrm{R}(\Omega)$ & $\mathrm{L}(\mathrm{cm})$ & Radius $(\mathrm{cm})$ & $\mathrm{A}\left(\mathrm{cm}^{2}\right)$ & $\mathrm{S} / \mathrm{cm}$ \\
\hline CNF-1000 & $845 \times 10^{3}$ & $7.69 \times 10^{-4}$ & $150 \times 10^{-7}$ & $7.06 \times 10^{-10}$ & 1.29 \\
HPP73-50 & $626 \times 10^{3}$ & $6.15 \times 10^{-4}$ & $135 \times 10^{-7}$ & $5.72 \times 10^{-10}$ & 1.72 \\
HPP73-40 & $748 \times 10^{3}$ & $7.69 \times 10^{-4}$ & $125 \times 10^{-7}$ & $4.90 \times 10^{-10}$ & 2.09 \\
HPP73-30 & $926 \times 10^{3}$ & $12.3 \times 10^{-4}$ & $100 \times 10^{-7}$ & $3.14 \times 10^{-10}$ & 4.28 \\
HPP73-20 & $931 \times 10^{3}$ & $9.23 \times 10^{-4}$ & $90 \times 10^{-7}$ & $2.54 \times 10^{-10}$ & 3.96 \\
\hline
\end{tabular}




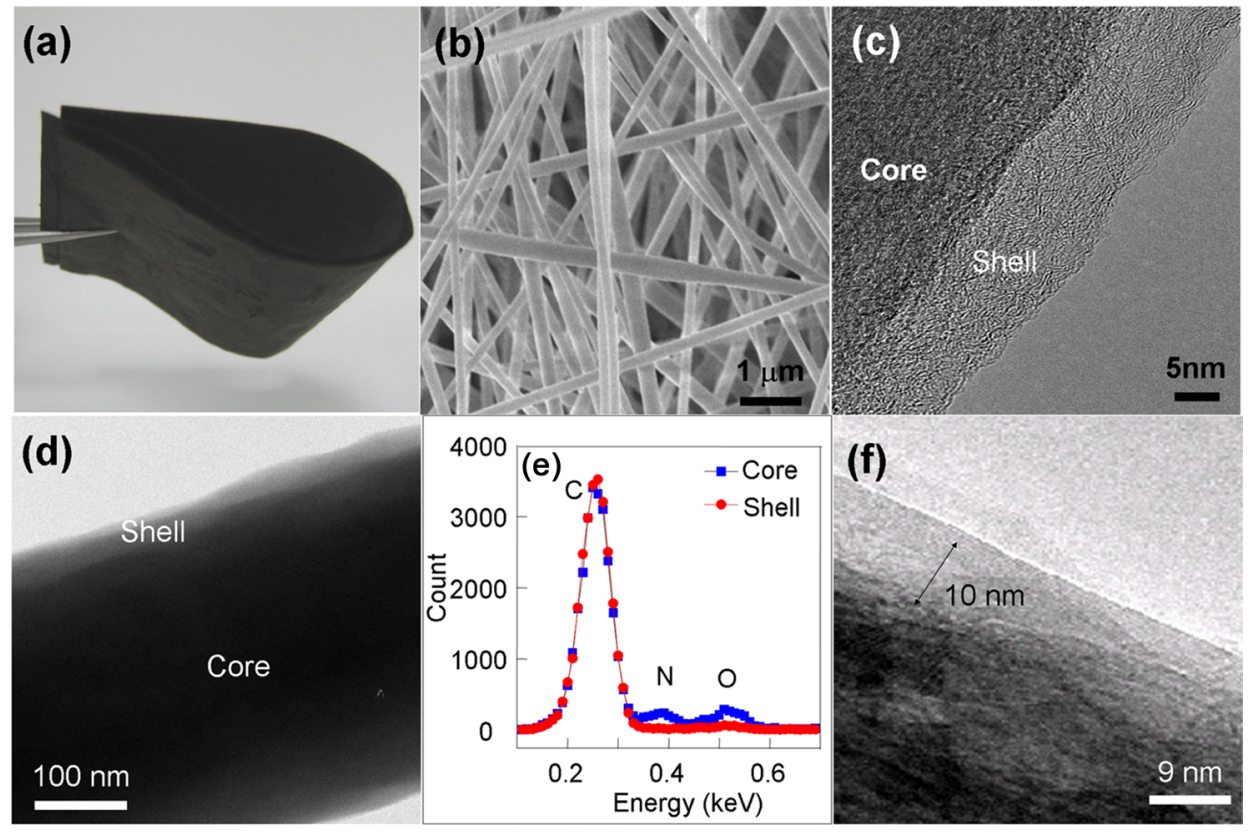

Fig. 8. Morphological structure of carbonized fibers from electrospinning of polyacrylonitrile/Cl-PP blends. (a) Photograph showing a bendable carbon nanofibers (CNFs). (b) Scanning electron microscopy image of CNFs. (c and d) Transmission electron microscopy (TEM) images of CNFs. (e) Energy-dispersive X-ray spectroscopy spectroscopy of air-stabilized nanofibers. (f) TEM of CNFs thermally treated up to $2800^{\circ} \mathrm{C}$ in argon [45]. PP: pitch precursor.

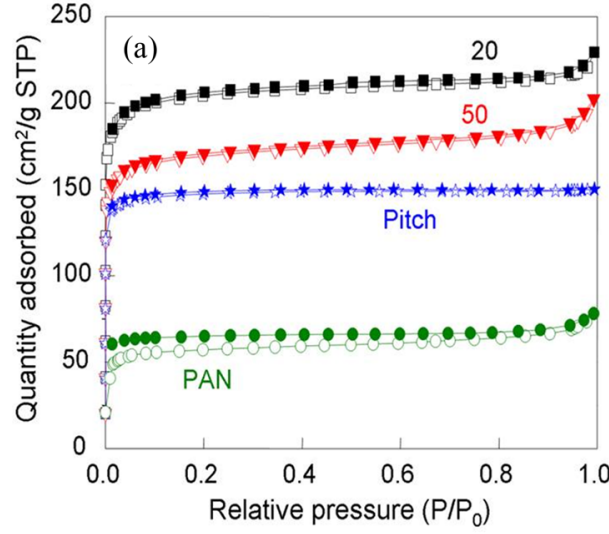

BET $\mathrm{N}_{2}$ Adsorption

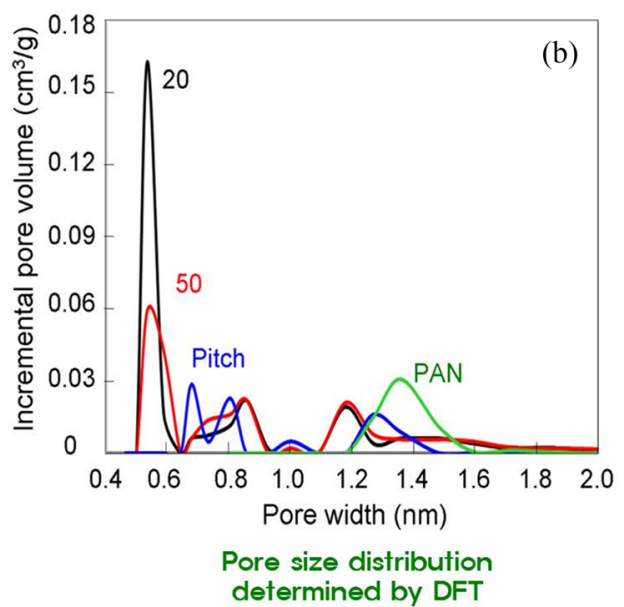

Fig. 9. (a) Nitrogen adsorption isotherms of the pure polyacrylonitrile (PAN)- and the PAN/pitch-derived CNFs as a function of pitch concentration in tetrahydrofuran, and (b) pore size distribution calculated by the density functional theory (DFT) method. Note that the blend ratio of PAN/pitch is constant at 7/3. BET: Brunauer-Emmett-Teller.

pared to improve the poor spinnability of the pitch due to the low molecular weight and/or low solubility. Kim et al. [45] and Bui et al. [50] reported that the PAN/pitch blend solutions presented better fiber-forming ability than pitch-based only solutions and also presented better electrical conductivity (Table 5) and a higher surface area than PAN-based solution only. HPP7320 is an identification of the PAN/Cl-PP content ratio of $7 / 3$ at Cl-PP 20\% in THF.

Using a PAN/pitch blend solution of $7 / 3$, a bendable web (Fig. 8b) with an average diameter of $150 \mathrm{~nm}$ without any beads was produced (Fig. 8c). Noticeably, the transmission electron microscopy image (Fig. 8d) shows that an individual CNF exhibits two-phase separation. Since there are substantial differences in the basic features of the two constituent polymers in the solution, the pitch with lower molecular weight was preferentially located in the shell $[45,50]$. Energy-dispersive X-ray spectroscopy observation of the two phases revealed the presence of nitrogen and oxygen in the core and only carbon in the skin of the air-stabilized fibers (Fig. 8e). The absence of nitrogen and oxygen atoms in the shell is attributed to the nature of the pitch and the dehydration reaction of the diffused and adsorbed oxygen atoms. Two phases and well-developed crys- 

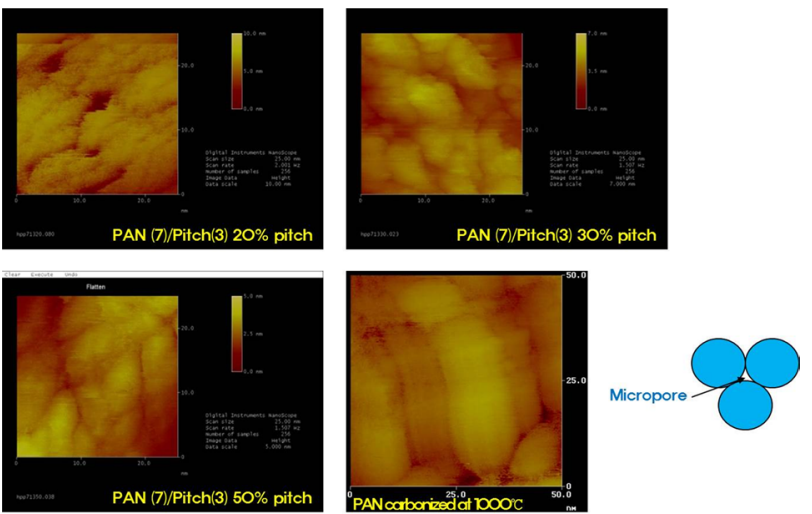

Fig. 10. Scanning tunneling microscopy (STM) images of polyacrylonitrile (PAN)/pitch-derived carbon nanofibers (CNFs) (a) 20, (b) 30, (c) 40 $w t \%$ pitch concentration, and (d) PAN-based CNF; high magnified STM images of (a-d) PAN/pitch-derived CNFs (a) 20, (b) 30, (c) 40, (d) $50 \mathrm{wt} \%$ pitch concentration in tetrahydrofuran.

talline layers were observed in the skin of the fiber, as shown in Fig. 8f

When the Cl-PP concentration in THF decreased at a fixed PAN concentration, smaller pore sizes were more predominantly developed, providing a higher Brunauer-Emmett-Teller (BET) surface area (Figs. 9a and b). The pore size distributions of PAN/Cl-PPderived CNFs, from density functional theory (DFT) calculations, exhibited tunable pore size distributions from $0.6 \mathrm{~nm}$ to $1.4 \mathrm{~nm}$ resulting from the variation of the pitch concentration. A scanning tunneling microscopy (STM) analysis provided more information on the domain size and micro-structure of the domains of the CNFs. As the pitch concentration increased, the shape of the surface changed from a small particle-like flat morphology to plate-like and to a large particle-like morphology. The domain size of the CNFs derived from PAN/pitch increased with an increase in pitch concentration (Figs. 10a-d). Naturally, the larger domain size resulted in larger pores with smaller specific surface areas. The domain structures observed by STM were consistent with the BET surface areas and pore size distributions.

The tunable pore size was examined to elucidate the effect of the pore size on the capacitance of a supercapacitor electrode. The electrochemical properties of the PAN/pitch-derived CNF webs were studied via $\mathrm{CV}$ in a $6 \mathrm{M} \mathrm{KOH}$ aqueous electrolyte solution.

According to the Ragone plot (Fig. 11), both the fibrous morphology and the optimized pore sizes allowed the PAN/pitchderived CNF electrode to achieve both a high energy density (ca. $15.0 \mathrm{Wh} \mathrm{kg}^{-1}$ ) and a high power density (ca. $100 \mathrm{~kW} \mathrm{~kg}^{-1}$ ) simultaneously. The Ragone plot also shows a higher power density can be obtained without significant degradation of the energy density.

\section{Concluding Remarks}

Precursor pitches can be synthesized from residual oil or from pure chemicals through thermal treatment or chemical reactions. The thermal treatment introduces radicals that form larger molecules and larger aromatic components in the molecule. On the

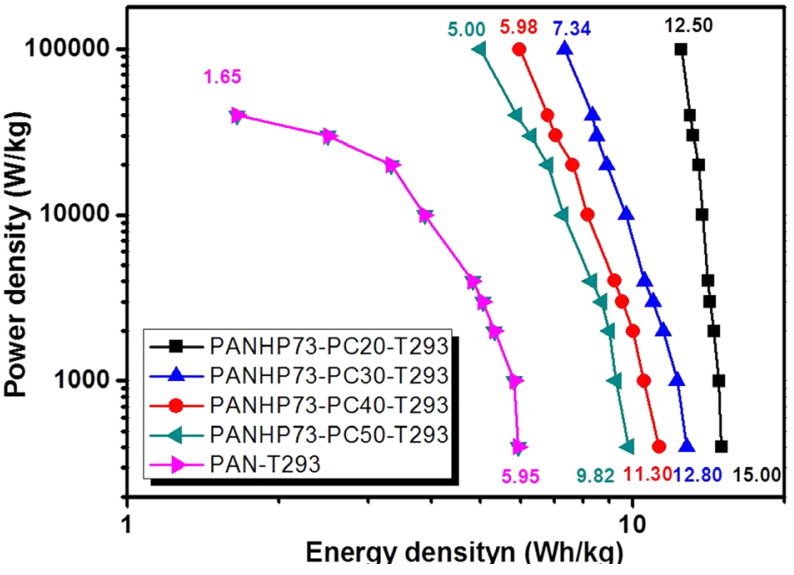

Fig. 11. Ragone plots (note that the $P C$ value indicates the pitch concentration in tetrahydrofuran) [45]. PAN: polyacrylonitrile.

other hand, condensation reactions through halogenation/dehydrohalogenation occur with hydrogen of the alkyl groups, allowing alkyl groups in the precursor molecules. Accordingly, the pitches are relatively more soluble and the molecular structure is rather linear, showing enhanced spinnability. The molecular structure could be controlled by optimization of the reaction rate resulting from the reaction temperature or the reactivity of halogens such as $\mathrm{Cl}_{2}$ and $\mathrm{Br}_{2}$. $\mathrm{Br}-\mathrm{EB}$ and Th-EB exhibit a Bingham behavior, suggesting that $\mathrm{Br}-\mathrm{EB}$ and Th-EB have a molten state similar to that of mesophase pitches. Such molecular structures of the precursors showed specific rheological properties that present behaviors with mesogen in the molecule from the condensed precursor of the bromination/dehydrobromination residue of naphtha cracking. The carbonized fibers from the precursor resulted in a higher tensile strength than that achieved through thermal treatment. The results suggest there is potential to enhance the mechanical properties by adjusting the molecular structure of the precursor. The elctrospun carbonized fibers introduce new possibilities for applications that exploit a high specific surface area with a fine-sized diameter and shallow pores on the surface. A narrower pore size distribution and larger specific surface area could be obtained from Cl-PP than from AN$\mathrm{PP}$ at the same activation conditions. There is also potential to use Cl-PP-based carbon fibers for electrodes in supercapacitors, gas storage, and catalyst support.

\section{Acknowledgements}

This work was supported by the Global Research Laboratory (2013056090) through the National Research Foundation of Korea (NRF) funded by the Ministry of Science, ICT and Future Planning.

\section{References}

[1] deVries J. Carbon fiber in the automotive industry... The holy grail or reality? Technologies Workshop on Low Cost Carbon Fiber Composites for Energy Applications, Oak Ridge, TN (2009).

[2] Kim BJ, Kato O, Miyawaki J, Mochida I, Yoon SH. High utiliza- 
tion of naphtha cracking residue as an effective raw material for pitch based carbon fiber. Proceedings of the 2nd Korea Institute Energy Research-Kyushu University Joint Symposium on Green System and Materials, Jeju, Korea (2012).

[3] Park SJ, Jang YS, Shim JW, Ryu SK. Studies on pore structures and surface functional groups of pitch-based activated carbon fibers. J Colloid Interface Sci, 260, 259 (2003). http://dx.doi.org/10.1016/ S0021-9797(02)00081-4.

[4] Park SJ, Kim BJ. Ammonia removal of activated carbon fibers produced by oxyfluorination. J Colloid Interface Sci, 291, 597 (2005). http://dx.doi.org/10.1016/j.jcis.2005.05.012.

[5] Park SJ, Jang YS, Rhee KY. Interlaminar and ductile characteristics of carbon fibers-reinforced plastics produced by nanoscaled electroless nickel plating on carbon fiber surfaces. J Colloid Interface Sci, 245, 383 (2002). http://dx.doi.org/10.1006/jcis.2001.8040.

[6] Park SJ, Kim KD. Influence of activation temperature on adsorption characteristics of activated carbon fiber composites. Carbon, 39, 1741 (2001). http://dx.doi.org/10.1016/S0008-6223(00)003055 .

[7] Yamaguchi C, Mondori J, Matsumoto A, Honma H, Kumagai H, Sanada Y. Air-blowing reactions of pitch: I. Oxidation of aromatic hydrocarbons. Carbon, 33, 193 (1995). http://dx.doi. org/10.1016/0008-6223(94)00127-L.

[8] Yu B, Wang C, Chen M, Zheng J, Qi J. Two-step chemical conversion of coal tar pitch to isotropic spinnable pitch. Fuel Process Technol, 104, 155 (2012). http://dx.doi.org/10.1016/j.fuproc.2012.05.007.

[9] Burgess WA, Pittman JJ, Marcus RK, Thies MC. Structural identification of the monomeric constituents of petroleum pitch. Energy Fuels, 24, 4301 (2010). http://dx.doi.org/10.1021/ef1002556.

[10] Zhuang MS, Thies MC. Extraction of petroleum pitch with supercritical toluene: experiment and prediction. Energy Fuels, 14, 70 (1999). http://dx.doi.org/10.1021/ef990141q

[11] Khanpour R, Sheikhi-Kouhsar MR, Esmaeilzadeh F, Mowla D. Removal of contaminants from polluted drilling mud using supercritical carbon dioxide extraction. J Supercrit Fluids, 88, 1 (2014) http://dx.doi.org/10.1016/j.supflu.2014.01.004.

[12] Da Porto C, Natolino A, Decorti D. Extraction of proanthocyanidins from grape marc by supercritical fluid extraction using $\mathrm{CO}_{2}$ as solvent and ethanol-water mixture as co-solvent. J Supercrit Fluids, 87, 59 (2014). http://dx.doi.org/10.1016/j.supflu.2013.12.013.

[13] Tomita K, Machmudah S, Wahyudiono, Fukuzato R, Kanda H, Quitain AT, Sasaki M, Goto M. Extraction of rice bran oil by supercritical carbon dioxide and solubility consideration. Sep Purif Technol, 125, 319 (2014). http://dx.doi.org/10.1016/j.seppur.2014.02.008.

[14] Ball GL, Gannon CR, Newman JW. Petroleum pitch: a major new carbon source. Proceedings of the 101st Annual AIME Meeting, San Francisco, CA (1972).

[15] Dongbu Hannong Co., Ltd. Preparation methods for isotropic pitch with high softening point. Korea Patents, 1999-012606, 1999 012607, 1999-012608, 1999-012609, 1999-012610 (February 25, 1999)

[16] Hanwha Chemical Co. Preparation methods of isotropic pitch precursor for carbon fibers. Korea Patents, 2000-0031269 (June 5, 2000)

[17] Hanwha Chemical Co. Preparation methods of isotropic pitch with high softening point. Korea Patents, 200-0105660 (November 29 2001)
[18] Greinke RA, O'Connor LH. Determination of molecular weight distributions of polymerized petroleum pitch by gel permeation chromatography with quinoline eluent. Anal Chem, 52, 1877 (1980). http://dx.doi.org/10.1021/ac50062a023.

[19] Shinohara K, Fujimoto H. The microstructure of highly-oriented graphite tape prepared from mesophase pitch by melt-blowing. Carbon, 50, 4926 (2012). http://dx.doi.org/10.1016/j.carbon.2012.06.022.

[20] Dmitriev AV. Microstructure peculiarities of carbon materials based on coal-tar pitch hardened on the surface of thermally expanded graphite flakes. Solid Fuel Chem, 47, 365 (2013). http:/ dx.doi.org/10.3103/S0361521913060025.

[21] Soltysiak S, Abendroth M, Kuna M, Dudczig S. Influence of the content of modified coal tar pitch powder on the strength of carbon bonded alumina $\left(\mathrm{Al}_{2} \mathrm{O}_{3}-\mathrm{C}\right)$. Adv Eng Mater, 15, 1230 (2013). http://dx.doi.org/10.1002/adem.201300173.

[22] Kumar R, Dhakate S, Mathur R. The role of ferrocene on the enhancement of the mechanical and electrochemical properties of coal tar pitch-based carbon foams. J Mater Sci, 48, 7071 (2013). http://dx.doi.org/10.1007/s10853-013-7518-z.

[23] Kim BJ, Kil H, Watanabe N, Seo MH, Kim BH, Yang KS, Kato O, Miyawaki J, Mochida I, Yoon SH. Preparation of novel isotropic pitch with high softening point and solvent solubility for pitchbased electrospun carbon nanofiber. Curr Org Chem, 17, 1463 (2013).

[24] Kim BH, Wazir AH, Yang KS, Bang YH, Kim SR. Molecular structure effects of the pitches on preparation of activated carbon fibers from electrospinning. Carbon Lett, 12, 70 (2011). http:// dx.doi.org/10.5714/CL.2011.12.2.070.

[25] Park SH, Kim C, Choi YO, Yang KS. Preparations of pitch-based CF/ACF webs by electrospinning. Carbon, 41, 2655 (2003). http:// dx.doi.org/10.1016/S0008-6223(03)00272-0.

[26] Kim BC, Lee SW, Eom YH, Yoon SH, Kim BJ, Mochida I. Rheological characterization of isotropic and anisotropic pitches. Proceedings of the 11th International Symposium on Carbon Saves the Earth: Novel Materials and Process for Energy Devices and Environmental Protections, Nagasaki, Japan (2013)

[27] Derbyshire F, Andrews R, Jacques D, Jagtoyen M, Kimber G, Rantell T. Synthesis of isotropic carbon fibers and activated carbon fibers from pitch precursors. Fuel, 80, 345 (2001). http://dx.doi. org/10.1016/S0016-2361(00)00099-5.

[28] Berrueco C, Álvarez P, Díez N, Granda M, Menéndez R, Blanco C, Santamaria R, Millan M. Characterisation and feasibility as carbon fibre precursors of isotropic pitches derived from anthracene oil Fuel, 101, 9 (2012). http://dx.doi.org/10.1016/j.fuel.2011.10.005.

[29] Vilaplana-Ortego E, Lillo-Ródenas MA, Alcañiz-Monge J, Cazorla-Amorós D, Linares-Solano A. Isotropic petroleum pitch as a carbon precursor for the preparation of activated carbons by $\mathrm{KOH}$ activation. Carbon, 47, 2141 (2009). http://dx.doi.org/10.1016/j. carbon.2009.04.020.

[30] Gierszal KP, Yoon SB, Yu J-S, Jaroniec M. Adsorption and structural properties of mesoporous carbons obtained from mesophase pitch and phenol-formaldehyde carbon precursors using porous templates prepared from colloidal silica. J Mater Chem, 16, 2819 (2006). http://dx.doi.org/10.1039/B603724K

[31] Li C, Jiang H, Wang Y, Wang Y. Hyperbranched poly(methyl methacrylate)s prepared by miniemulsion polymerization and their (non)-Newtonian flow behaviors. Polymer, 52, 376 (2011). http:// dx.doi.org/10.1016/j.polymer.2010.11.050. 
[32] He C, Zhou D. Existence and asymptotic behavior for an incompressible Newtonian flow with intrinsic degree of freedom. Math Methods Appl Sci, 37, 1191 (2014). http://dx.doi.org/10.1002/ mma.2880.

[33] Haldenwang R, Kotzé R, Chhabra R. Determining the viscous behavior of non-Newtonian fluids in a flume using a laminar sheet flow model and Ultrasonic Velocity Profiling (UVP) system. J Braz Soc Mech Sci Eng, 34, 276 (2012). http://dx.doi.org/10.1590/ S1678-58782012000300008.

[34] Esmael A, Nouar C, Lefèvre A, Kabouya N. Transitional flow of a non-Newtonian fluid in a pipe: experimental evidence of weak turbulence induced by shear-thinning behavior. Phys Fluids, 22, 101701 (2010). http://dx.doi.org/10.1063/1.3491511.

[35] Chonnam National University. High density carbon nano-fiber felt with unidirectional orientation and preparation of the felt and application to supercapacitor electrode. Korea Patent Application, 10-2013-0126578 (October 23, 2013).

[36] Guo H, Lu M, Liang L, Zheng J, Zhang Y, Li Y, Li Z, Yang C. Enhancement in the thermal and dynamic mechanical properties of high performance liquid crystalline epoxy composites through uniaxial orientation of mesogenic on carbon fiber. J Appl Polym Sci, 131 (2014). http://dx.doi.org/10.1002/app.40363.

[37] Park SH, Kim C, Yang KS. Preparation of carbonized fiber web from electrospinning of isotropic pitch. Synth Met, 143, 175 (2004). http://dx.doi.org/10.1016/j.synthmet.2003.11.006.

[38] Yan H, Mahanta NK, Majerus LJ, Abramson AR, Cakmak M. Thermal conductivities of electrospun polyimide-mesophase pitch nanofibers and mats. Polym Eng Sci, 54, 977 (2014). http://dx.doi. org/10.1002/pen.23638.

[39] Koombhongse S, Liu W, Reneker DH. Flat polymer ribbons and other shapes by electrospinning. J Polym Sci B, 39, 2598 (2001). http://dx.doi.org/10.1002/polb.10015.

[40] Naito K, Yang JM, Kagawa Y. Tensile properties of high strength polyacrylonitrile (PAN)-based and high modulus pitch-based hybrid carbon fibers-reinforced epoxy matrix composite. J Mater Sci, 47, 2743 (2012). http://dx.doi.org/10.1007/s10853-011-6101-8.

[41] Naito K, Tanaka Y, Yang JM, Kagawa Y. Tensile properties of ultrahigh strength PAN-based, ultrahigh modulus pitch-based and high ductility pitch-based carbon fibers. Carbon, 46, 189 (2008) http://dx.doi.org/10.1016/j.carbon.2007.11.001.

[42] Saiyasombat C, Maensiri S. Fabrication, morphology, and structure of electrospun pan-based carbon nanofibers. J Polym Eng, 28 5 (2008). http://dx.doi.org/10.1515/POLYENG.2008.28.1-2.5.

[43] Kuo HH, Chern Lin JH, Ju CP. Tribological behavior of fastcarbonized PAN/phenolic-based carbon/carbon composite and method for improving same. Wear, 258, 1555 (2005). http://dx.doi org/10.1016/j.wear.2004.10.009.

[44] Hu HL, Ko TH, Kuo WS, Su YJ. Influence of adding MCMBs into carbon/carbon composites reinforced by PAN Base No-woven carbon fabrics on their microstructure and performances. Mater Lett, 59, 2746 (2005). http://dx.doi.org/10.1016/j.matlet.2005.04.050.

[45] Kim BH, Yang KS, Kim YA, Kim YJ, An B, Oshida K. Solvent-induced porosity control of carbon nanofiber webs for supercapacitor. J Power Sources, 196, 10496 (2011). http://dx.doi.org/10.1016/j jpowsour.2011.08.088.

[46] Grzyb B, Albiniak A, Broniek E, Furdin G, Marêché JF, Bégin D. $\mathrm{SO}_{2}$ adsorptive properties of activated carbons prepared from polyacrylonitrile and its blends with coal-tar pitch. Microporous Mesoporous Mater, 118, 163 (2009). http://dx.doi.org/10.1016/j. micromeso.2008.08.032

[47] Machnikowski J, Grzyb B, Machnikowska H, Weber JV. Surface chemistry of porous carbons from N-polymers and their blends with pitch. Microporous Mesoporous Mater, 82, 113 (2005). http:// dx.doi.org/10.1016/j.micromeso.2005.03.004

[48] Yao Y, Liu L, Chen J, Dong Y, Liu A. Enhanced oxidation performance of pitch fibers formed from a heterogeneous pitch blend. Carbon, 73, 325 (2014). http://dx.doi.org/10.1016/j.carbon.2014.02.070.

[49] Yan H, Mahanta NK, Wang B, Wang S, Abramson AR, Cakmak M Structural evolution in graphitization of nanofibers and mats from electrospun polyimide-mesophase pitch blends. Carbon, 71, 303 (2014). http://dx.doi.org/10.1016/j.carbon.2014.01.057.

[50] Bui NN, Kim BH, Yang KS, Dela Cruz ME, Ferraris JP. Activated carbon fibers from electrospinning of polyacrylonitrile/pitch blends. Carbon, 47, 2538 (2009). http://dx.doi.org/10.1016/j.carbon.2009.05.007. 